\title{
Using Subjectivity and Emotion to Reconsider Participatory Natural Resource Management.
}

\section{MARGARET C MORALES}

Corresponding Author: Iharris@ires.ubc.ca

\section{LEILA M. HARRIS}

University of British Columbia, 2014

Final version: Morales, M., and L. Harris (2014) Using Subjectivity and Emotion to Reconsider Participatory Natural Resource Management. World Development 64, 703-712. DOI: 10.1016/j.worlddev.2014.06.032

Citations of this work should use the final version as noted above 


\section{Table of Contents}

SUMMARY.

1. INTRODUCTION: PARTICIPATION AS A MEANS AND ENDS FOR NATURAL RESOURCE MANAGEMENT

2. CRITIQUES OF PARTICIPATION AND STATE OF KNOWLEDGE ....

3. TOWARDS A TWO-PRONGED APPROACH AND THE POTENTIAL OF SUBJECTIVITY AND EMOTION IN PARTICIPATORY NRM

(a) Towards a Two-Pronged approach: individual and context ................................. 8

(b) Subjectivity and Emotion in the NRM Realm 12

(c) Definitions and recent contributions at the intersection of subjectivity, emotions, and NRM

4. MOVING FORWARD WITH SUBJECTIIVTY AND EMOTION - PATHWAYS FOR MORE EQUITABLE AND SUSTAINABLE PARTICIPATORY GOVERNANCE

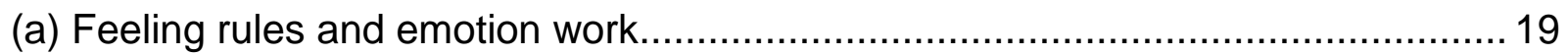

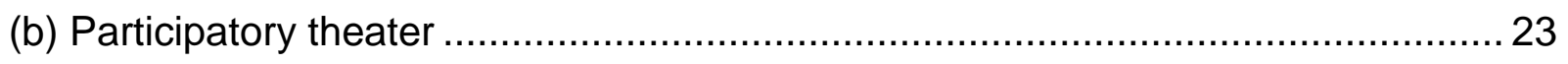

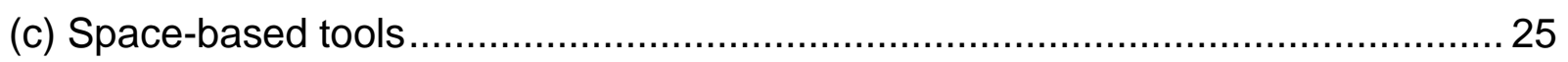

(d) Community-Led Total Sanitation: A Case Study In the Potential and Problematics of Employing Emotion and Subjectivity-Based Tools in NRM ................................2 27

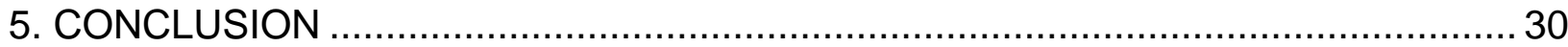




\section{SUMMARY}

This article examines what attention to subjectivity and emotion can bring to understandings

of participatory resource governance. This focus highlights limitations of common participatory governance approaches, as well as possible ways forward. Attention to these dynamics makes it clear that for participatory governance interventions to be equitable and sustainable they must attend simultaneously to structural and institutional dynamics, as well as an individuals' experience of participation. Moving forward, we offer some suggestions of new tools and approaches (e.g. emotion work, participatory performance, and spatial tools) that emerge from explicit consideration of emotional and subjective dimensions of participatory resource governance

Keywords: - emotion, subjectivity, participation, empowerment, equity, management 


\section{INTRODUCTION: PARTICIPATION AS A MEANS AND ENDS FOR NATURAL RESOURCE MANAGEMENT}

Community participation in natural resource management (NRM) has been increasingly understood as necessary to achieve both environmental sustainability and greater social equity. Several key policy milestones have served to establish this consensus, including the Aarbus convention on Access to Information, Public Participation in Decision Making, and Access to Justice in Environmental Matters (UNECE, 1998), and the Dublin Principles for Water Governance (WMO, 1992), both of which stress participation as one of several pillars for effective and equitable resource governance. Indeed, many now recognize participation as a dominant or hegemonic policy discourse (see Goldin, 2013a, and Sultana, 2009b for discussion of participation as hegemonic in water governance). Even with continued calls for participation, and a seeming consensus surrounding its importance to successful NRM, the literature is filled with examples of participatory governance failure in the natural resource realm. In addition, participatory governance initiatives frequently serve to further marginalize certain populations. This highlights a key disconnect—on the one hand there is a strong sense that participation is necessary and desirable for effective NRM. Yet, on the other, there is an undeniable reality that sustainable and equitable participation is exceedingly difficult to achieve in practice. We take this fundamental tension regarding the imperatives and difficulties of participation as our point of departure.

From this starting point, this article makes two linked arguments. First, while implicit in the literature, we suggest that it is useful to be explicit about the necessity of a 'two-pronged approach' to participatory resource governance that holistically and simultaneously attends to both the individual and the broader socio-cultural context (cf. Cornwall, 2004a, 2004b; Gaventa, 2004). Doing so helps to avoid common pitfalls in participatory initiatives, including those inherent to 
individual-focused empowerment and similar approaches. Our second contribution is more novel and represents the key contribution of our work. Specifically, we develop a case for closer engagement with emotion and subjectivity_concepts largely stemming from feminist, sociological, and allied literatures -to enrich the theory and practice of participatory NRM. This second contribution is fundamentally linked to the first in that we understand emotion and subjectivity not as isolated or personal/individual experiences, but as influenced by, and constituted through, contextual factors and relationships. Precisely because of their attention to the intersection between individual experience and broader socio-cultural dynamics, emotion and subjectivity offer insights and ways forward into a more holistic and two-pronged approach to participatory NRM. We develop both of these linked arguments in turn, analyzing what they can illuminate in terms of ongoing and past failures of participatory NRM, as well as creative starting points for future initiatives.

The discussion that follows draws on examples from a range of resource realms, including forestry and agriculture, although we rely most heavily on examples related to gender and water management — the subfield closest to our own research domain. Although we focus primarily on participatory governance for natural resource management, we consider that the insights here are also relevant for top-down NRM interventions, as well as for participatory governance in nonresource domains. As we highlight, emotion and subjectivity offer fertile ground to understand community social dynamics generally, and as such are likely to be rich concepts for further engagement in a range of fields. This insight builds on a range of contributions across the social sciences and humanities that have similarly drawn attention to emotion, affect, and subjectivity as offering key insights for a range of social and political processes (e.g. Christensen, Rothgerber, Wood, \& Matz, 2004; Katz, 1999; Van Wijnendaele, 2013; Woodward \& Lea, 2010). 
To proceed, we first provide a brief review of common critiques of participatory NRM. As these discussions are already well elaborated, we move quickly on to engage the concepts of subjectivity and emotion, and how this focus allows us to make sense of participatory management failures. We then turn to consider what novel ideas and techniques these concepts may bring to participatory governance more generally, offering a core contribution on themes and potential avenues for enriched attention that have only minimally been highlighted in the NRM realm to date. To this end, we explore several tools that directly confront and engage emotions and alternative subject formation in ways that might be useful for participatory NRM. Detailing these as starting points for further exploration, rather than as recommendations for the field, our aim is to open up new issues for further consideration and debate. An in-depth discussion of Community Based Total Sanitation (CLTS) helps us to elaborate some of these points, also drawing necessary attention to some of the drawbacks and problems of such techniques.

\section{CRITIQUES OF PARTICIPATION AND STATE OF KNOWLEDGE}

Over the last two decades, theories of participation in resource governance have come under heavy critique (Agarwal, 2001; Cooke \& Kothari, 2001; Hickey \& Mohan, 2004). In general, critiques emphasize several primary points: 1) a sense that participatory institutions and processes lack understanding of, or engagement with, community power dynamics, and as such might reinforce inequalities rather than assist in overcoming them; 2) even when contextual power dynamics are recognized, they are often addressed only superficially, for instance, through quantitative goals (e.g. quotas or counting attendance of underrepresented groups at meetings); and 3) participation may serve as a mechanism for devolving responsibility to communities, placing both the problem and solution in the community realm, with the potential to further tax local resources or to invoke and 
operationalize key forms of 'governmentality.' Several examples help to illustrate these linked concerns.

A primary critique is that participatory interventions risk reinforcing inequalities within communities, at times normalizing unequal access to resources (Cooke \& Kothari, 2001; McKinnon, 2007; O’Reilly, 2010). Concepts of elite capture (Aguilar, 2005; McKinnon, 2007; Ribot, 2002) and participatory exclusions (Agarwal, 2001; Barnes, 2013; Harris, 2005; Sultana, 2009b) suggest that continued marginalization is likely to occur if participatory interventions do not explicitly address the broader context and pathways of marginalization. The impact of these marginalizations potentially goes beyond social equity concerns. For instance, research has shown that inequalities of this type can result in less effective institutions for resource management, compromising ecological sustainability goals (Agarwal, 2001; 2009; Aguilar, 2005; Carney, 1996; Molinas, 1998; O’Reilly, 2010; Westermann, Ashby, \& Pretty, 2005). With respect to gender specifically, many have argued that gender-aware community engagement will enrich decisions and management agendas, for instance, by attending to diverse local knowledges (Agarwal, 2001; 2009; Bennett, Davila-Poblete, \& Rico, 2005; Delgado, 2005). Further, it is believed that participatory engagement will improve project buyin, improve monitoring capacity in the community, and avoid situations where certain populations' resource needs are excluded in management decisions, thereby reducing violations or illegal extraction of resources that undercut management goals (Agarwal, 2001; 2009; Bennett et al., 2005; Westermann et al., 2005).

Even when participatory institutions do attempt to address social inequalities, they may do so superficially, in ways that might similarly consolidate inequitable or unsustainable resource governance regimes. As such, it is increasingly recognized that there is a need to move beyond sole consideration of formal mechanisms that maintain power relationships, such as legal enforcement, 
and to consider power dynamics more broadly, infused in all aspects of social interactions and daily life (e.g. accepted social norms and practices, cf. Foucault, 1979). Numerous authors have explored case studies in which NRM interventions that were meant to be participatory did not adequately address the myriad of ways in which power inequalities functioned and were maintained, with the end result of further entrenchment of exclusions along gendered, racial, or socio-economic lines (see: Aguilar, 2005; Delgado, 2005; O’Reilly, 2004).

Finally, there is also concern that participatory NRM interventions can also reinforce operations of power by devolving responsibilities to individuals and communities. This often results in increasing an already disproportionate work burden (Agarwal, 2000; O’Reilly, 2006), at times for those with the least capacity or knowledge to undertake additional responsibilities (Harris, 2009; O’Reilly, 2010; Walby, 2005). For instance, programs that emphasize women's specialized ecological knowledge, or the need for gender equitable governance institutions, may end up imposing considerable burden on women to undertake more responsibility (see: Agarwal, 2001; 2009; Bennett et al., 2005; O’Reilly, 2006; 2010). Particularly when we consider the broader political and economic context of neoliberalism, such interventions may reinforce or justify diminished state involvement, such as shifts away from regulatory functions or reduced state capacities to monitor resources (Harris, 2009).

Together these critiques suggest that there is a persistent need to attend to the more subtle ways in which power dynamics function, such as through social norms and expectations, as well as to broader political and economic contexts, which together influence the processes and outcomes of participatory management. We now turn to our two primary arguments, first elaborating how a twopronged approach, simultaneously attentive to individuals and context, speaks to the above concerns. Secondly we examine the potential contributions of work that engages the concepts of 
subjectivity and emotion to address these concerns, including ways that this focus may provide novel ways forward. .

\section{TOWARDS A TWO-PRONGED APPROACH AND THE POTENTIAL OF SUBJECTIVITY AND EMOTION IN PARTICIPATORY NRM}

\section{(a) Towards a Two-Pronged approach: individual and context}

The first, more minor, point we make relates to the necessity of a two-pronged approach in participatory NRM - one that deals simultaneously with the individual, and their broader context (political, economic, social, institutional, cultural). We find this point implicit in much of the recent literature on participatory NRM (see for example, contributions in Hickey \& Mohan, 2004; or more broadly, Jupp, 2008), although not always clearly and succinctly stated. Among other authors who have called for the need to simultaneously attend to the individual and context, Gaventa (2004) calls for attention both to the strength of citizens' voices as well as to the responsiveness of institutions to foster more democratic and effective governance. Similarly, O’Reilly (2010) writes, “Gendered participatory approaches... are inherently conservative when they do not question the social inequalities behind the particular difficulties that women face" (O’Reilly, 2010, p. 53). The basic point is that while at times empowerment and participatory approaches aim to include underrepresented populations, it is not enough to simply have more people from diverse groups (be it gender, racial, class or other types of diversity), attend meetings and raise their voices. Unless broader social, cultural and institutional structures also shift to support that engagement, participation will be superficial, short-lived, or confined to the individual who is able to challenge 
social mores, even if uncomfortable or challenged.

Failures of participatory governance approaches that do not take a two-pronged approach are replete in the literature. A brief discussion of 'empowerment' serves to concretize this point. 'Empowerment' has been a major focus of policy and academic literatures over the past several decades. This is particularly true for those concerned with development goals and participatory process_-especially for those focused on enhancing engagement with marginalized populations (Kenny \& Clarke, 2010). Often empowerment programs conceptualize the individual in terms of skills, assets, or self-perception, and seek to offer technical skills and trainings to transform the individual (Agarwal, 2001; Aguilar, 2005; Kenny \& Clarke, 2010; O’Reilly, 2008b). As such, discourses and practices of empowerment most often place the individual at the center of the interaction - the individual is situated as both the problem and solution to sustainable resource governance, development, or other problematic (Kenny \& Clarke, 2010; O’Reilly, 2010; Rankin, 2001; Van Wijnendaele, 2013). A major shortcoming of this approach is that it fails to recognize the broader context and more general societal or cultural changes that might be needed to support those shifts (cf. Paluck, 2012).

Delgado’s (2005) description of an irrigation project in the Peruvian Andes provides a useful example of the shortcomings common to empowerment initiatives. In this case, participation in project planning was conditioned on land ownership — a reality only for men. An initiative seeking to stimulate broader community participation in the project might focus on women, perhaps seeking to make female community members landowners, thus qualifying them for involvement in the project. In this case, even as women did come to own land, men continued to argue that women could not participate in project decision-making, claiming they were unable to "talk in public" and that they "lack character in making decisions, and most are shy and illiterate" (Delgado, 2005, p. 119). By in 
large, in this context, "the women saw their exclusion from the project as normal up to a point because they understood and had internalized Llullucha's communal customs" (p. 117, Llullucha is a small village in the Peruvian Andes). In brief, attention focused on the individual women, while very little consideration was given to entrenched societal norms that hindered women's participation and represented obstacles to any individual overcoming or countering these norms.

As another example, consider a case study offered by Manase, Ndamba, \& Makoni (2003). These authors note that a shortage of women with the technical expertise to fill decision-making positions in a Zimbabwe water management project severely constrained the potential of "achieving gender balance in decision-making" (p. 971). This shortage was the result of social systems that made access to professional training in the water sector particularly difficult for women (linked to social expectations and definitions of femininity). In this case, an empowerment approach might seek to offer education or skills training to women so that they could obtain the qualifications understood to be necessary for informed decision-making. However, even if an individual woman is provided with training, she might continue to face obstacles in the face of the broader social context that doesn't value, or validate, a woman's knowledge or capacity in that domain. As these examples help to illustrate, empowering marginalized community members to be involved in decision-making without also challenging the broader structural conditions of that participation is likely to be hollow and unsustainable, even deeply frustrating for those individuals who do speak up or otherwise engage in practices that challenge norms (Agarwal, 2001; Aguilar, 2005; O’Reilly, 2008a). Indeed, the focus on the individual may in fact displace attention from broader political and economic issues, suggesting the change can and should happen at the individual level (see Maniates, 2001), without questioning dominant or hegemonic frameworks in which this change is supposed to happen. As others have noted, 'integrative paradigms' of this type are likely to achieve little from an equity perspective in the long-term (Walby, 2005). Research in political science and psychology has 
increasingly focused on norm change as critical to fostering changes needed to challenge 'wicked' or intractable problems rather than focusing solely on individual attitudes (Paluck, 2012; Raymond et al., 2014).

On the other side as well, simply changing the rules or institutions of governance is unlikely to empower individuals to challenge underlying social norms. As Gaventa (2004) writes, "simply creating new institutional arrangement for participatory governance will not necessarily be more inclusive or more pro-poor" (25), nor will it automatically create the ability to maintain these changes (Harris, 2009). Though the involvement of traditionally excluded participants in formal institutions may, over long time periods, alter social norms, for instance with 'role model' ideas and similar approaches (e.g. Ennis-McMillan, 2005; and more broadly, Paluck, 2009), these efforts can often be supported and made more robust with simultaneous attention to individual experience and capabilities.

We take the considerable evidence of a frequent disconnect between individual- focused efforts and broader social, cultural, or contextual norms as reason to develop new conceptual tools that centrally and simultaneously attend to individual and community-level changes. As we explore below, the linked concepts of emotions and subjectivity offer a fertile starting ground in this effort. In brief, subjectivity and emotion - concepts largely stemming from feminist, sociological, and allied literatures - reference an understanding that individual experiences (and thus actions) are not isolated, but embedded within their specific social, political, cultural, and economic contexts. They highlight how social norms are not only 'out there' at the community level, but are often internalized and self-perpetuated as individuals work to align their emotions and senses of self with accepted social practices and hierarchies (Hoschild, 1979; Kesby, 2005; Raymond \& Weldon, 2013; Rutten, 2006). Applied to participatory NRM, acknowledging these linkages between individuals and their 
context offers forceful suggestion that if participatory initiatives are to be successful, they must simultaneously engage individual capability and experience, as well as broader social and institutional contextual factors that mold and influence individual behaviors and senses of self (Christensen, et al., 2004; Kesby, 2005; Rutherford, 2007; Walby, 2005). Thus, these two concepts may not only illuminate reasons for participatory governance failures, as we have explored above, but may also suggest pathways forward in the field. The next section further elaborates these points.

\section{(b) Subjectivity and Emotion in the NRM Realm}

Work in the social sciences and humanities related to subjectivity and emotion has blossomed of late, with a small subset of this literature linking these concepts with resource governance. Several authors have highlighted that decisions regarding resource use and management are not strictly based on rational decision-making frameworks, but rather are highly subjective, and influenced by emotions, relationships, power dynamics, and shifting subjectivities (Nightingale, 2011; 2013; Sultana, 2009a; 2011; Wong \& Sharp, 2009; Wutich \& Ragsdale, 2008). Similarly, other work has suggested that engagement with participatory governance mechanisms can be a deeply emotional experience, triggering experiences such as pride, shame, or sadness (Goldin, 2010; 2013a; Sultana, 2009a).

Here we present a brief summary of the state of knowledge regarding the linked concepts of subjectivity and emotion before further developing their applicability and potential to enrich understandings or participatory NRM. It is worth noting that we do not directly engage the concepts of subjectivity and emotion from psychological or broad humanities perspectives, but rather seek to build on how these terms have been engaged in social science discussions, including those specific to natural resource governance. 


\section{(c) Definitions and recent contributions at the intersection of subjectivity, emotions, and NRM}

Subjectivity refers to how one understands oneself within a social context -one's sense of what it means and feels like to exist within a specific place, time, or set of relationships. Subjectivity may reference a sense of identity (e.g. to feel as a woman or as a racial or ethnic minority), but also recognizes that this sense of self is tightly connected and influenced by context and may in fact shift in relation to changing circumstances (Foucault, 1979; Nightingale, 2011; 2013; Sultana, 2009a). In referencing both the individual sense of self, and one's embodied negotiation of that sense in a particular (and shifting) context, the concept of subjectivity invites direct reference to power-laden aspects of context—both in terms of space and time. Importantly, subjectivity highlights the ways that individuals may internalize social expectations of what counts as normal or acceptable behavior. Kesby (2005) writes that power structures are in fact "most effective and most insidious" when internalized and normalized so that "self-expectation, self-regulation, and self-discipline generate compliant subjects" (p. 2040) who themselves reproduce unequal power relationships (see also: Foucault, 1979; Raymond et al., 2013; Van Wijnendaele, 2011).

Related to NRM, work by political ecologists has focused on how subjectivities (e.g. gendered or ethnic) are renegotiated in relation to resource use and access (Harris, 2006; Nightingale, 2011; 2013; Sultana, 2009a). Providing a rich example of these dynamics, Nightingale (2011) describes how fishermen in Scottish in-shore fisheries typically feel competent and proud as fishermen when in their boats, or with their families. However, what it feels like to be a fisherman their subjectivities - can change dramatically when in meeting rooms discussing conservation with policy makers and scientists. In these more formalized contexts the fishermen often feel out of place 
and powerless, and may be cast unknowledgeable, or as irresponsible and greedy exploiters of natural resources (Nightingale, 2011; 2013). Accentuating this contextual shift, Nightingale (2011) writes that in these formal spaces, "The exercise of power changes in profound ways, and these people end up in a more defensive position relative to their occupation" (p. 125).

Interest in subjectivity has also increasingly been taken up in discussions of environmentality, environmental citizenship, and the formation of 'green subjects' who identify with environmental care or management (Agrawal, 2005; Author, 2011; Haggerty, 2007; Latta \& Wittman, 2012; Robbins, 2006; Wong \& Sharp, 2009). Others have stressed the power-laden processes of subjectification, including the ways in which new 'green' sensibilities or regulatory regimes about resources condition the 'conduct of conduct', ushering in new regimes of power (Blundo \& Le Meur, 2009; Rutherford, 2007).

Turning to the linked issue of emotion, we follow Sultana (2011), Nightingale (2013) and others in defining emotions not as isolated, personal mental states, but rather as "relationally produced between peoples and places” (Sultana, 2011, p. 164) (see also Van Wijnendaele, 2011). Similar to the concept of subjectivity, this framing defines emotion not as individualized, nor as solely cognitive, but rather as lived and experienced in bodies, and in contextually specific ways (see also: Katz, 1999; Woodward \& Lea, 2010). Emotions may often be triggered in response to power structures, and are frequently experienced in relation to whether one violates or meets expectations related to social norms. Highlighting the role of emotions in processes of self-regulation, Rutten (2006) refers to Hoschild's (1979) research on emotion work and writes, "any ideological stance... contains implicit 'feeling rules,' which are guidelines for how one ought to feel in specific situations" (Rutten, 2006, p. 356) (see also Kesby, 2005; Raymond et al., 2013; Van Wijnendaele, 2011). We return to the concept of feeling rules in Section IV. 
Several recent works deserve mention for their useful elaboration of the importance of emotions in NRM (including Agarwal, 2001; Goldin, 2010; Nightingale, 2011; Sultana, 2011; Wutich, 2009, Wutich \& Ragsdale, 2008; see Van Wijendaele, 2013 for work related to the importance of emotions in participatory work more broadly). Returning to Nightingale's work with fishermen in Scotland's inshore fisheries $(2011,2013)$, the fishermen's shifting subjectivities according to changing context were largely experienced and articulated as shifting emotions, from power, pride and competence, to powerlessness, defensiveness, and discomfort. Wutich (2009) also provides a case study of water issues in Cochabamba, Bolivia, highlighting how women experience stress as they are forced to haggle over water prices or chase after water trucks to acquire sufficient water for their households. These types of contributions offer fruitful foundations to move forward towards more nuanced and complex appreciation of how emotions are tied to NRM, whether through participation in management, or conservation practice.

The emotion of shame has long been explored as key to reinforcing social relationships, functioning as a mechanism by which individuals internalize the "cultural criteria for self-evaluation" (Rutten, 2006, p. 356). Feelings of shame are often triggered when subjects feel they are falling short of, or transgressing, social expectations. A key element of shame is often recognition, whereby one recognizes how others may see and understand them (ie. to be exposed for wrongdoing, or the shame of recognition in terms of one's bodily nakedness). As well, shame may trigger isolation from community, senses of inferiority, or vulnerability (Katz, 1999). Raymond et al. (2013) write that shaming can act as "a powerful form of enforcing and maintaining social norms" (7). All of these elements suggest that shame is particularly powerful in highlighting processes of self-regulation (and peer-to-peer monitoring) in accordance with social norms and power structures that make challenging these norms difficult (ibid; Kesby, 2005). 
Works by Goldin (2010), Sultana (2009a), and Agarwal (2010) focus specifically on shame in

NRM, examining ways in which it may act as a deterrent to participation (or at least signal frustration and difficulties in participation). Geographer Farhana Sultana (2009a) explores how shame and honor are used to reinforce gendered subjectivities in the context of rural Bangladesh, with the effect shaping gender-water relations and accepted practices for water collection. Anthropologist Jacqueline Goldin (2010) explores how feelings of shame and trust influence the participatory process in water governance boards in South Africa by comparing two different rural communities_-one predominantly white that had historically benefited from water policies under apartheid, and a nearby coloured community (n.b., this an accepted racial-demographic designation in the South African context). Her work finds that white farmers report feelings of pride, fulfillment, and satisfaction when engaging with water management. By contrast, farmers from the coloured community report lack of confidence in their water-related knowledges, and considerable discomfort, and even shame, when they engage in participatory frameworks. She writes that "The absence of knowledge, the unequal power relationships between water users, and the inhibition of agency, frustrate the process of participation because the production of trust is inhibited and feelings of shame, that aggravate issues of social exclusion and negate social agency, are activated” (p. 197). As a result water users or elected water board councilors often choose to remain silent in council meetings rather than meet with shame due to their lack of proficiency with the accepted 'scientific' language; in turn, this silence serves to further entrench their social exclusion (p. 209). As another example, while not explicitly framed as exploring emotional dimensions of participation, economist Bina Agarwal's (2010) work is also suggestive. In the context of forest management in India, Agarwal finds that women were more likely to attend meetings of decision-making bodies when accompanied by other women. Undoubtedly, the women felt more support, or less threat of being attacked, singled out or shamed when accompanied by other women. The community-led total 
sanitation (CLTS) model, which uses shame to trigger participation and alter open defecation practices, is a key example of using shame and other emotions to stimulate particular forms of participation in the realm of sanitation (Mehta, 2011). As we explore through a case study of CLTS below, this example brings to the fore the potential for, and problems of, explicit deployment and manipulation of emotions in participatory NRM initiatives.

Taking the above examples together, attention to emotion and subjectivity not only makes sense of high failure rates in participatory governance initiatives and reinforces the need for a more holistic and two-pronged approach to NRM, but also helps to operationalize this two-pronged approach by highlighting ways forward. For example, while experiences such as shame are unlikely to engender success or inclusive engagement, dimensions of participatory processes that trigger pride or a sense of validation can be key to ensuring broad and meaningful participation. We now turn to a fuller consideration of emergent and novel perspectives regarding participatory governance efforts that flow from enriched attention to these concepts.

\section{MOVING FORWARD WITH SUBJECTIIVTY AND EMOTION - PATHWAYS FOR MORE EQUITABLE AND SUSTAINABLE PARTICIPATORY GOVERNANCE}

What does it mean to propose participatory governance initiatives that are simultaneously attentive to context and individual experience? What tools and concepts that might enable stronger focus on emotions and subjectivity in the practice of participatory NRM? Here we provide several examples of specific tools that might serve this focus, highlighting both the potential, and problematics, of doing so. At first glance, highlighting the two-pronged approach may appear to 
simply suggest employing some traditional tools in tandem, such as individual empowerment approaches (via skills training or increased economic freedom), along with new governance regulations (such as reserving seats on decision-making boards for a diverse representation of community members). However, we believe that engagement with emotion and subjectivity helps to uncover other novel and creative approaches to engendering more equitable and sustainable participatory governance. In this section we highlight several of these possibilities related to emotion-work, participatory performance, and spatial dynamics. As noted, we also call for considerable caution as these tools bring with them significant difficulties and great potential to further entrench inequalities.

The insights and tools we present here may be understood as working in two ways. First, they endeavor to make visible the subtle, normalized, and invisible power dynamics present in communities. It is only through explicit recognition of these processes that core power relations can be understood and, possibly, challenged. As Raymond and Weldon (2013) point out, "Drawing conscious attention to norms and subjecting them to scrutiny can make us aware of choices we are making every day of which we had previously been unaware. This greater self-awareness and scrutiny, in turn, can be an important step toward changing the behavior prompted by the norm." (3-4) (see also: Van Wijnendaele, 2013). Second, moving from this recognition to rewrite possibilities for participation requires new narratives of social relationships. As Kesby (2005) writes, "Successful, sustainable empowerment outflanks existing frameworks by constituting, deploying, and normalizing new powers" (p. 2052; see also Raymond et al., 2013). Thus, these tools also suggest ways that social scripts, meanings, and experiences may be re-crafted to open up spaces for alternative interactions.

As this is a nascent field of inquiry, we are only able to offer a few suggestions along these lines. It is critical to emphasize, again, that by no means are these possibilities foolproof, 
unproblematic, or easy to implement across contexts. Indeed, we emphasize a strong imperative for considerable caution and ongoing critical reflection. As we elaborate through a detailed discussion of CLTS, engaging emotions and seeking to purposely alter subjectivities is a pathway that is clearly fraught. Yet, we find it instructive to begin this conversation, and start a process of interrogating these types of possibilities and tools more fully, and offer the following thoughts as a springboard for further engagement. We expect that much more could be said (and hope will be), particularly through enlivened discussion on these issues, empirical studies, or perhaps, more explicit engagement with psychology and other fields of inquiry.

\section{(a) Feeling rules and emotion work}

Hoschild's (1979) concept of 'emotion work' references the "the act of trying to change in degree or quality an emotion or feeling" (p. 561), suggesting that individuals have an active role in their emotions, rather than being passive subjects of them. Emotion work aims to change existing 'feeling rules,' (recall 'feeling rules' are accepted guidelines for how one ought to feel in particular situations), and thereby change the meaning of social interactions and power dynamics. Speaking to our focus on the two-pronged approach to participatory governance initiatives, emotion work begins with a focus on how power dynamics are felt and normalized at an individual level, while also working to recognize and transform these "rules" at a broader communal level. Emotion work tools may be used to transform an individuals' understanding and experience of their public participation in NRM, resisting and challenging social norms and feeling rules that have been restrictive or oppressive, and ultimately encouraging marginalized groups to actively engage in management and decision-making (see also: Raymond et al., 2013; Van Wijnendaele, 2011).

Though discussions of emotion work parallel those related to empowerment in many ways, 
the concepts differ importantly. Similar to elements of empowerment models, the expectation with emotion work is that changes at the individual level will engender broader transformations (of expectations, social narratives, or institutions). However, emotion work explicitly emphasizes emotions as part of an individual's interaction with broader contextual factors (e.g. feeling rules), rather than isolated personal events. As such, a framework of emotion rules stems from a recognition of ways that individual action is profoundly shaped and molded by context.

Hoschild (1979) highlights three different areas of emotion work: 1) cognitive; 2) bodily; and 3) expressive. Here we explore examples of each of these. In her work with Indian laborers in plantations in the Philippines, sociologist Roseanne Rutten (2006) explores the emotion of shame and subjectivities of clientelism and how these impact workers' experiences and actions. Rutten discusses how strong authority structures in patron-client relationships created difficulties for laborers in discussing concerns with their bosses, and describes how shame functions in this context as an obstacle to worker activism, in that "face-to-face confrontations with authority figures may be thwarted by the emotional and behavioral disposition of workers" (p. 353). This patron-client divide is exaggerated by racialized differences, as laborers are typically of Indian descent while patrons generally identify as Ladino (or of mixed race). Rutten examines how Hoschild's (1979) cognitive, bodily, and expressive emotion work may be used to develop other emotions and subjectivities as a means of changing patron-client relationships and power dynamics and enabling greater participatory action.

Cognitive emotion work centers on changing "images, ideas, or thoughts in the service of changing the feelings associated with them" (Hoschild, 1979, p. 562). The core idea is that by changing connotations of pervasive images or ideas, normalized expectations or practices associated with these may be confronted and imagined in new ways. A specific example of cognitive emotion 
work is the transformation of a reference group — the standard against which individuals may compare themselves to measure how closely they align with socially agreed upon norms. In the context of plantations in the Philippines, Rutten (2006) describes how laborers of Indian descent were often implicitly or explicitly compared to mixed-race Ladinos (e.g. in terms of valuing light skin, slight physique, and so forth). Indeed the standards implied by this reference group would be exceedingly difficult, if not impossible, for plantation laborers to achieve given both genetic differences, as well as the transformations their bodies undergo as a result of their laboring practices-including darkened skin and strong physique associated with being outside and engaging in agricultural labor. Rutten (2006) describes how the worker body was a source of shame for many laborers who "judged themselves as 'ugly' in comparison to the richer people in town" (p. 367) who by comparison were thinner or lighter skinned. To combat this, worker-activists in these communities campaigned to change the workers' reference group. This involved a campaign to glorify the worker body through drawings and theater performances representing the body's physical strength to "hold its ground in public confrontations," (ibid, p. 367). The purpose of this campaign was to encourage a sense of pride and self-confidence amongst workers with the goal of shifting power dynamics and relationships with patrons. As we discussed above, shifts from shame to pride are of particular interest given that shame often makes participation more difficult, while pride might be associated with more visible and confident involvement in public spaces and interactions (ibid; see Goldin, 2010; 2013b; Van Wijnendaele, 2011).

Aguilar (2005) provides another example of reference group and cognitive emotion work. Her work describes a hand pump implementation project in Costa Rica which offered technical training manuals with images made from a gender aware perspective, showing both women and men participating in hand pump construction. While not always effective, in this case the claim is made that the inclusion of women in these representations encouraged both men and women to not see 
project implementation as solely a masculine task, and encouraged women to actively learn hand pump construction methods (see O’Reilly, 2010 for counter-examples related to the ineffectiveness of gender equitable imagery in the realm of gender and sanitation in India).

A myriad of embodied practices also offer potential to alter social norms and expectations. Returning to Hoschild (1979), bodily emotion work is described as "the attempt to change somatic or other physical symptoms of emotions (i.e., trying to breathe slower, trying not to shake)" (p. 562). Similarly, expressive emotion work refers to efforts to change expressive gestures in ways that help to also alter feelings (e.g. trying to smile or to cry) (Hoschild, 1979). This is different from simply displaying emotions, as the effort to embody a different sentiment may actually alter the emotion itself (consider for instance, that the act of smiling actually releases endorphins that can have the effect of making one feel happier).

Rutten (2006) provides a specific example of how bodily and expressive emotion work may be used to counter hegemonic social expectations. She describes how many indigenous workers had experienced angry outbursts in confrontations with authority figures that resulted in further shaming these workers, and discouraging future encounters. Union activists targeted this by offering trainings that helped individuals speak in a controlled manner, to choose words with care, and to act with diplomacy in emotionally charged situations. The purpose of these trainings was to change workers' experience of their encounters with bosses to something that validated their sense of self and engendered confidence.

Again, while we would not claim that these examples can be neatly applied in other contexts, or to the participatory NRM realm writ large, we nonetheless find them suggestive in terms of opening new pathways for investigations that take seriously embodied and situated emotional and subjective experiences of participation. For instance, if one experiences shame in speaking up in a 
meeting, emotion work efforts seek to create emotion rules and norms might by practicing, scripting, or embodying different interactions in ways that solidify confidence rather than fear or embarrassment. There may also be considerable risks related to emotion work tools, and we consider some of these in a detailed exploration of community-led total sanitation initiatives towards the end of this section.

\section{(b) Participatory theater}

Linked to the examples of rescripting interactions mentioned in the bodily and expressive emotion work examples above, other practitioners have examined theatre, performance, and roleplaying as means of creating new social scripts for participant actors (Boal, 2000; Guhrs, Rihoy, \& Guhrs, 2006; Kesby, 2005; Quinlan, 2010; Rutten, 2006). Important among these is the 'Theatre of the Oppressed' movement, first elaborated by Augusto Boal, which utilizes a number of theatrical forms to facilitate and encourage engagement from diverse audiences on a variety of socially relevant issues. One type of this practice, often referred to as Forum Theater, uses actors to perform scenes of common social interactions in which an individual may feel oppressed or sidelined. Audience members are encouraged to stop the scene, and personally enter into it to act out new ways in which the interaction could be played, with the aim of imagining more equitable and productive scripts (Boal, 2000). Performed actions are meant to both upset emotion rules and their attendant power dynamics, and stimulate new emotions, such as confidence.

Kesby's (2005) exploration of the use of role-play as part of Stepping Stones, a widely used program in HIV education, serves as a concrete example of the use of role-playing in participatory interventions. As a part of the program participants are encouraged to use role-playing techniques to reflect on their own experiences with HIV and to 'rehearse' alternative social interactions and 
conversations regarding life with HIV. The aim of these techniques is to open "material spaces in which ordinary people themselves can... renegotiate sociosexual behavior, and improve communication around HIV" (p. 2043). Kesby writes that many participants, particularly women, reported that they felt more able to openly discuss sexual health after participation in Stepping Stones. Yet other examples also exist in the realm of health and diversity, including the Really? Campaign, a program to encourage interventions by participants to question racist, sexist or homophobic statements (Really?, 2014), or the 'rewriting' of one's own cancer experience through the use of video and creative expression to create new, more empowering biographies of life with the disease (even if fictionalized, see the Cancer's Margins Project, 2014). In these examples the goal is to recreate situations and rewrite scripts with the goal of creating more empowering interactions, and more supportive environments for marginalized communities. Recall as well the rewriting of scripts and of interactions we witness with Rutten's (2006) case study on engaging laborers to play-act new types of confrontations with patrons regarding working conditions. In the realm of NRM, theater performances scripted and acted by local community members has been used to engage communities in discussions of resource use and management, as well as to share with broader audiences of policy-makers and donors about the struggles of NRM (Guhrs, et al., 2006).

Though such performances may be clearly contrived, performance tools rely on the idea that "power, resistance, and transformation can all be produced by situationally conscious human action" (Kesby, 2005, p. 2046). Thus the performance becomes a means of openly acknowledging the presence and workings of accepted social hierarchies and norms in daily interactions (Kesby, 2005; Rutten, 2006). By destabilizing these social norms through a conscious recognition of their presence, a range of new responses and actions become possible. The act of performance also begins a process of normalizing a new social script through repeated performance, forming a foundation of support and sustainability for new social structures (Kesby, 2005; Rutten, 2006, more in line with 
Butlerian notions of performativity, Butler 1990, 1993). Even if real life does not go exactly

according to scripts as rehearsed, participants will be more prepared, and perhaps more likely, to challenge traditional roles and norms than before.

Again, our discussion of the applicability of these tools to participatory NRM is not to expressly endorse these pathways and techniques. Nor do we suggest that they will work, or are prudent, in all contexts or resources realms. In fact performance work has received some significant critique. Referring to Kothari's (2001) work, Kesby (2005) writes that when a foreign NGO or other outside organization encourages community members to participate in performance-based tools, these performances may be largely for the benefit of external audiences, particularly to the degree that they oversimplify daily realities (Kesby, 2005, p. 2042). Similarly, Guhrs et al. (2006) warn against the ways that theater can oversimplify or misrepresent a community's situation and message. For our purposes here, we find that these possibilities nonetheless raise provocative openings in terms of what might be possible through renewed engagement at the intersections of participation, subjectivity, and emotional experience.

\section{(c) Space-based tools}

While emotion work tools begin by embedding the individual within their context, other work has examined how contexts shape the participatory interactions that occur within them. Many theorists, particularly geographers, have explored how space is fundamental in any exercise of power (Massey, 1994; cf. Foucault, 1984). In line with this, the role of physical space in communicating, confronting, and shifting power dynamics has already received some attention for its impact on experiences of participation (Cornwall, 2004a; 2004b; Gaventa, 2004; Nightingale, 2011; Raymond et al., 2013; Sultana, 2009a). Spaces are gendered, classed, raced, and affect the subjectivities of those 
who inhabit, come into contact with, avoid, or are barred from them. In short, spaces are produced by, and productive of, the social relationships that exist (or are performed) within them (Boal, 2000; Hickey \& Mohan, 2004). Manipulations of space can thus be used to enable, reinforce, or undermine particular subjectivities, senses of self, or emotional interactions (O’Reilly, 2010; Sultana, 2009a).

As an example, power dynamics may sometimes be made visible within a space based on how some stakeholders or participants are privileged, perhaps communicated by where they sit (i.e., who receives a chair versus who sits on the floor). Recall the Nightingale $(2011 ; 2013)$ example described above. In this case fishermen were invited to enter into the offices and meeting rooms of policy makers to discuss management practices. Nightingale writes, "The space of the meeting room, then, produces particular kinds of subjects for both the fishermen and policymakers that sets them literally, on opposite sides of the room" (129). The fishermen not only described feeling out of place in these contexts, but also subjected to the preconceptions held by policy makers. As policy makers were the 'inviters' in this case, their assumptions shaped meeting agendas, and reinforced notions of the "normative fishing subject" (ibid, 129). This and similar explorations can produce significant insights into the importance of space and context in participatory interactions, and how these may be used to mold particular emotional encounters, and subjectivities in ways that might support more equitable participation rather than reinforce social hierarchies (see also work on emotion, affect and space by Woodward \& Lea, 2010).

Several examples demonstrate how space has been central to enabling or disabling participatory action. Looking at the example of Kettleman City in California, resistance by Spanish speaking farm workers was solidified when they were asked to move towards the back of a meeting room where the translator stood. Recalling 'back of the bus' resistance from the civil rights movements, these workers pressed forward, 'Adelante, adelante' insisting that their concerns, and 
bodies, would not be relegated to distant corners of the room (Cole \& Foster, 2000). Similarly, while the World Social Forum in Porto Alegre (2005) was significant in that it was one of the first times a specific space was allocated for indigenous people, critics also noted the relatively marginalized spaces to which these groups were relegated. In brief, attention to how a space is created, by whom, and in what relation to other spaces may have significant impact on the interactions that occur within it. These factors can radically influence how power dynamics flow through a space, how open or available it may be to community presence and participation, and finally, what opportunities may exist for using it to recast broader social dynamics (Cornwall, 2004a; 2004b; Gaventa, 2004; Kesby, 2005). Again, we suggest that attentiveness to one's emotions and senses of self are potentially instructive to understand when these dynamics inhibit meaningful participation, or how spaces can be altered to create greater senses of engagement or inclusion. In addition to observing the interactions that occur within spaces, it is also possible to research, and track, emotional experiences of those spaces, or indeed, even indicators of joy, enjoyment, stress, or other embodied and emotional experiences (cf. Katz, 1999; Goldin, 2013b).

\section{(d) Community-Led Total Sanitation: A Case Study In the Potential and Problematics of Employing Emotion and Subjectivity-Based Tools in NRM}

As we have noted, though attention to emotion and subjectivity offers interesting possibilities for pushing participatory NRM forward, these tools do not come without potential pitfalls and ethical challenges. A detailed discussion of Community-Led Total Sanitation (CLTS) allows us to further examine these tensions. The CLTS movement began in rural Bangladesh in 2000 and has rapidly grown as a 'successful' approach in the sanitation sector given its proven effectiveness at reducing or even eliminating open defecation in villages (with important associated 
public health benefits of reducing diarrheal disease). CLTS differs from more traditional sanitation interventions in that its focus is not on infrastructure provision, but rather on behavioral change. In the CLTS approach, behavioral changes are 'ignited' by the purposeful triggering of specific emotions, particularly shame and embarrassment, in order to arrest patterns of open defecation (consider overlap with our discussion of emotion work, above). Mehta \& Movik (2011) describe how participatory methods are used to "cause an upsurge of various emotions in the community, including the feelings of shame, embarrassment and disgust.... The realization that they are quite literally ingesting one another's 'shit' mobilizes them into initiating collective local action to improve the sanitation situation in the community" (Mehta \& Movik, 2011, p. 3-4). Such participatory methods are often tailored to the social norms in a specific context; they include marking piles of feces left in the open with the person's name, throwing stones at people seen defecating in the open, and creating maps highlighting households with and without toilets (Mahbub, 2008). The literature is replete with proclamations of the success of CLTS initiatives in achieving changes in sanitation behavior much more quickly than more conventional approaches to sanitation. Mehta ascribes this success to CLTS's focus precisely on collective behavior change fueled and triggered by attention to the emotions of participants (most notably, shame).

Despite its reported successes, CLTS has also been subject to significant critique (Bartram, Charles, Evans, O’Hanlon, \& Pedley, 2012; Chatterjee, 2011) regarding the ethics of shaming and embarrassing individuals. In brief, the efforts seem to 'blame the victims' since often it is impoverished individuals or those with few resources who might engage in open defecation. Chatterjee (2011) reports on some even more extreme 'triggering' tactics she witnessed employed by villagers participating in a CLTS initiative; these included photographing people while defecating in the open and displaying these photographs publicly. In an interview we conducted with a WASH sector NGO in Ghana, the efforts had gone as far as videotaping people engaging in open 
defecation and showing those videos in central parts of the village (interview by author, 2012).

Chatterjee (2011) also describes local government threats to cut off household water and electricity service until homeowners agreed to construct latrines. As Chatterjee writes, "humiliation and fear are strikingly effective tools... As we told UNICEF, the ultimate success of the project in Karnataka was founded on community-led coercion - not a utiopian democratic upsurge" (blog post dated 9 June 2011).

CLTS serves as an important example of how tools which aim at manipulating emotions can easily become double-edge swords, perhaps 'effective' from a public health standpoint, but also destructive to a community, and from a social justice perspective. Such tactics become particularly troublesome when we recognize that, as discussed in Section II, factors such as socio-economic status and gender may influence who is in a position to lead an intervention, and who is more likely to be the recipient of the shame tactics (i.e., those who continue to defecate in the open may be those who can least afford to build or use a toilet).

While the case of CLTS serves as a warning about the very real ethical challenges of emotion-based tools in participatory interventions, it is perhaps also true that things do not always have to go this way. CLTS is a prime case study of these tactics, but is also perhaps unique in that it is premised off of pitting community members against one another, singling out and identifying those not in compliance with the initiative. This seems to be an approach with high probability of destructive outcomes. In addition, CLTS focuses on triggering what might be termed 'negative' emotions (i.e. shame and embarrassment as opposed to pride and self-respect). We could argue that such negative emotions serve to further underscore unbalanced power dynamics, rather than encouraging equity. Perhaps different types of emotion work, that focus more on positive emotions, and that serve to bring communities together rather than to divide them, hold greater promise in 
terms of the equitable and sustainable participatory NRM that we envision and aim to work towards.

The point remains, while we are not promoting techniques and approaches that explicitly engage emotions and alternative subject formation, our aim here has been to argue that emotions and subjectivity are key to participatory NRM, and as such deserve greater attention and consideration. To do so, we have offered some opening lines of thought and discussion, hoping to signal spaces for further opportunities and engagement and exploration.

\section{CONCLUSION}

Though gaining momentum, still relatively little work is done in the NRM sector that includes explicit focus on emotional and subjectivity dynamics of participatory initiatives. Attention to these dynamics has the potential to bring renewed discussion and fresh insights to this work. As we have emphasized through conceptual discussion and a range of examples, these concepts foreground the intimate connections between an individual and one's community and institutional context. As such, focus on subjectivity and emotion has great potential to reveal the workings of the subtle power dynamics that mold, restrict, enable, and condition an individual's experience and actions. It is precisely these subtle ways in which power works in communities that has such an enormous impact on the success or failure of community engagement. Taking an individual and their context as tightly connected and linked suggests that sustainable and equitable participatory governance models must take a two-pronged approach: equally and simultaneously attentive to an individual's experience of participation, and how broader socio-cultural dynamics influence this experience. Using emotion and subjectivity as lenses through which to reexamine past participatory resource governance initiatives reveals that approaches to engendering participation often place emphasis on either individuals or their context, but rarely deal with these in tandem. Moving 
forward, attention to emotion and subjectivity in participatory interactions illuminates some new conceptual spaces, as well as innovative tools, to remap the terrain and possibilities of participatory NRM. The goal of these examinations is to support participation that is more inclusive and equitable, particularly for marginalized groups and individuals.

Our hope is that this article will spark renewed conversation and further interdisciplinary engagement on participatory resource management, as well as top-down NRM, or other dimensions of community development similarly served by this type of discussion. The opportunities we highlighted in Section IV for ways forward in supporting sustainable participatory governance should not be read as prescriptions. Rather we see these as explorations into the wide range of potential new approaches to enabling and supporting participatory governance models that take seriously the subtle power dynamics of daily life. We remain convinced that taking seriously emotional and subjective dimensions of these engagements is important for understanding and enabling individual well-being in these encounters. We also consider that it is likely essential to foster institutions and governance mechanisms that are robust, equitable, and more likely to foster ecologically sustainable management over the long-term. 


\section{REFERENCES}

Agarwal, B. (2000). Conceptualising environmental collective action: why gender matters. Cambridge Journal of Economics, 24, 283-310.

Agarwal, B. (2001). Participatory exclusions, community forestry, and gender: An analysis forSouth Asia and a conceptual framework. World Development, 29(12), 1623-1648.

Agarwal, B. (2009). Gender and forest conservation: The impact of women's participation in community forest governance. Ecological Economics, 68(11), 2785-2799.

Agarwal, B. (2010). Does women's proportional strength affect their participation?Governing local forests in South Asia. World Development, 38(1), 98-112.

Agrawal, A. (2005). Environmentality: Technologies of Government and the Making of Subjects. Durham:

Duke University Press.

Aguilar, L. (2005). Water as a Source of Equity and Empowerment in Costa Rica. In V. Bennett, S. Davila-Poblete, \& M. N. Rico (Eds.), Opposing Currents: The Politics of Water and Gender in Latin America (pp. 123-134). Pittsburgh, PA: University of Pittsburgh Press.

Barnes, J. (2013). Who is a Water User? The politics of gender in Egypt's water user associations In L. Harris, J. Goldin, \& C. Sneddon (Eds.) Water Governance in the Global South: Crisis, Marketization, Participation. London: Routledge.

Bartram, J., Charles, K., Evans, B., O'Hanlon, L., \& Pedley, S. (2012). Commentary on communityled total sanitation and human rights: should the right to community-wide health be won at the cost of individual rights? Journal of $W$ ater and Health 10 (4), 499-503.

Bennett, V., Davila-Poblete, S., \& Rico, M. N. (Eds.). (2005). Opposing Currents: The Politics of Water and Gender in Latin America. Pittsburgh, PA: University of Pittsburgh Press.

Blundo, G., \& Le Meur, P.Y. (Eds.). (2009). The Governance of Daily Life in Africa: Ethnographic Explorations of Public and Collective Services. Leiden: Brill Academic Publishers.

Boal, A. (2000). Theatre of the Oppressed. ( ${ }^{\text {rd }}$ ed.) . (C. McBride, M. L. McBride, \& E. Fryer, Trans.). London: Pluto. (Original work published 1979)

Butler, J. (1990). Gender Trouble: Feminism and the Subversion of Identity. New York, NY: Routledge.

Butler, J. (1993). Bodies that Matter: On the Discursive Limits of 'Sex'. New York, NY: Routledge.

Cancer's Margins (2014). Cancer's Margins. Retrieved from http://www.lgbtcancer.ca/

Carney, J. (1996). Converting the wetlands, engendering the environment: the intersection of gender 
with agrarian change in Gambia. In R. Peet, \& M. Watts, (Eds.), Liberation ecologies:

Environment, development, social movements (pp. 165-87). New York, NY: Routledge.

Chatterjee, L. (2011). Time to acknowledge the dirty truth behind community-led sanitation. The

Guardian. Retrieved from http://www.theguardian.com/global-development/poverty-

matters/2011/jun/09/dirty-truth-behind-community-sanitation

Christensen, P., Rothgerber, H., Wood, W., \& Matz, D. (2004). Social Norms and Identity

Relevance: A Motivational Approach to Normative Behavior. Personality and Social Psychology Bulletin, 30, 1295-1309.

Cole, L., \& Foster, S. (2000). From the Ground up: Environmental Racism and the Rise of the Environmental Justice Movement. New York: New York University Press.

Cooke, B., \& Kothari, U. (2001). Participation: the new tyranny. London: Zed Books.

Cornwall, A. (2004a). New democratic spaces? the politics and dynamics of institutionalised participation. IDS Bulletin, 35(2), 1-10.

Cornwall, A. (2004b). Spaces for transformation? Reflections on issues of power and difference in participation in development. In S. Hickey, \& G. Mohan (Eds.), Participation: From Tyranny to Transformation? (pp. 75-91). New York, NY: Zed Books.

Delgado, J. R. V. (2005). Irrigation Management, the Participatory Approach, and Equity in an Andean Community. In V. Bennett, S. Davila-Poblete, \& M. N. Rico (Eds.), Opposing Currents: The Politics of Water and Gender in Latin America (pp. 109-122). Pittsburgh, PA: University of Pittsburgh Press.

Ennis-McMillan, M. C. (2005). Women, Equity, and Household Water Management in the Valley of Mexico. In V. Bennett, S. Davila-Poblete, \& M. N. Rico (Eds.), Opposing Currents: The Politics of Water and Gender in Latin America (pp. 137-153). Pittsburgh, PA: University of Pittsburgh Press.

Foucault, M. (1979). On Governmentality. Ideology and Consciousness, 6, 5-21.

Foucault, M. (1984). Space, knowledge, and power. In P. Rabinow (Ed.), The Foucault reader (pp. 239-56). New York, NY: Pantheon.

Gaventa, J. (2004). Towards participatory governance: assessing the transformative possibilities. In S. Hickey \& G. Mohan (Eds.), Participation: From Tyranny to Transformation? (pp. 25-41). New York, NY: Zed Books.

Goldin, J. A. (2010). Water Policy in South Africa: Trust and Knowledge as Obstacles to Reform. Review of Radical Political Economics, 42(2), 195-212. 
Goldin, J. A. (2013a). The participatory paradigm: anathema, praise, confusion. In L. Harris, J. Goldin, \& C. Sneddon (Eds.) Water Governance in the Global South: Crisis Marketization, Participation. London: Routledge.

Goldin, J. A. (2013b). From Vagueness to Precision: Raising the Volume on Social Issues in the Water Sector. Water Policy, 15, 309-324.

Guhrs, T., Rihoy, L., \& Guhrs, M. (2006). Using theatre in participatory environmental policy making. Participatory Learning and Action, 55, 87-93.

Haggerty, J. H. (2007). I'm not a greenie but... Environmentality, eco-populism and governance in New Zealand: Experiences from the Southland Whitebait fishery. Journal of Rural Studies, 23, 222-237.

Harris, L. (2005). Negotiating inequalities: democracy, gender, and politics of difference in water user groups of Southereastern Turkey. In F. Adaman \& M. Arsel (Eds.), Environmentalism in Turkey: Between Democracy and Development? (pp. 185-200). London: Ashgate Publishing Company.

Harris, L. (2006). Irrigation, gender, and social geographies of the changing waterscapes of southeastern Anatolia. Environment and Planning D: Society and Space, 24(2), 187-213.

Harris, L. (2009). Gender and emergent water governance: comparative overview of neoliberalized natures and gender dimensions of privatization, devolution and marketization. Gender, Place \& Culture, 16(4), 387-408.

Hickey, S., \& Mohan, G. (Eds.). (2004). Participation: from tyranny to transformation? New York, NY: Zed Books.

Hoschild, A. R. (1979). Emotion Work, Feeling Rules, and Social Structure. American Journal of Sociology, 85(3), 551-575.

Jupp, E. (2008). The feeling of participation: Everyday spaces and urban change Geoforum (39), 331 343.

Katz, J. (1999). How Emotions Work Chicago, London: University of Chicago Press.

Kenny, S., \& Clarke, M. (2010). Introduction. In S. Kenny \& M. Clark (Eds.), Challenging Capacity Building: Comparative Perspectives (pp. 3-20). New York, NY: Palgrave Macmillan.

Kesby, M. (2005). Retheorizing Empowerment-through-Participation as a Performance in Space: Beyond Tyranny to Transformation. Journal of Women in Culture and Society, 30(4), 2037-2065.

Kothari, U. (2001). Power, Knowledge, and Social Control in Participatory Development.In B. Cooke \& U. Kothari (Eds.), Participation: The New Tyranny? (pp. 139-152). London: Zed 
Books.

Latta, A. \& Wittman, H. (Eds.). (2012). Environment and Citizenship in Latin America: Natures, Subjects, and Struggles. New York, NY: Berghahn Books.

Mahbub, A. (2011). Social Dynamics of CLTS: Inclusion of Children, Women and Vulnerable. CLTS Conference at IDS Sussex. Sussex: IDS.

Manase, G., Ndamba, J., \& Makoni, F. (2003). Mainstreaming gender in integrated water resource management: the case of Zimbabwe. Physics and Chemistry of the Earth, 28(20), 967-971.

Maniates, M. (2001). Individualization: plant a tree, buy a bike, save the world? Global Environmental Politics?, 1(3), 31-52.

Massey, D. (1994). Space, place and gender. Minneapolis, MN: University of Minnesota Press.

McKinnon, K. (2007). Postdevelopment, Professionalism, and the Politics of Participation. Annals of Association of American geographers, 97 (4), 772 - 786.

Mehta, L. \& S. Movik (2011). Shit Matters. The potential of community-led total sanitation. London and Sterling, VA: Stylus / Practical Action Publishing.

Molinas, J. (1998). The Impact of Inequality, Gender, and External Assistance And Social Capital on Local-Level Cooperation. World Development, 26(3), 413-431.

Nightingale, A. (2013). Fishing for nature: the politics of subjectivity and emotion in Scottish inshore fisheries management. Environment and Planning A (45), 2362- 2378.

Nightingale, A. (2011). Beyond Design Principles: Subjectivity, Emotion, and the (Ir)Rational Commons. Society and Natural Resources, 24, 119-132.

O’Reilly, K. (2004). Developing Contradictions: Women's Participation as a Site of Struggle Within an Indian NGO. The Professional Geographer, 56(2), 174-184.

O’Reilly, K. (2006). “Traditional” women, “modern” water: Linking gender and commodification in Rajasthan, India. Geoforum, 37, 958-972.

O’Reilly, K. (2008a). Insider/Outsider Politics: Implementing Gendered Participation in Water Resource Management. In B. Resurreccion \& R. Elmhirst (Eds.), Gender and Natural Resource Management: Livelihoods, Mobility and Interventions (pp. 195-212). London: Earthscan.

O’Reilly, K. (2008b). “Where the Knots of Narrative Are Tied and Untied”: The Dialogic Production of Gendered Development Spaces in North India. Annals of the Association of American Geographers, 97(3), 37-41.

O’Reilly, K. (2010). Combining sanitation and women's participation in water supply: an example from Rajasthan. Development in Practice, 20(1), 45-56. 
Paluck, E. L. (2012). The dominance of the individual in intergroup relations research:

Understanding social change requires psychological theories of collective and structural phenomena. Behavioral and Brain Sciences, 35(6), 443-444.

Paluck, E. L. (2009) What's in a Norm? Sources and Processes of Norm Change Journal of Personality and Social Psychology 96 (3), 594-600.

Quinlan, E. (2010). New action research techniques: Using Participatory Theatre with health care workers. Action Research, 8(2), 117-133.

Rankin, K. N. (2001). Governing development: neoliberalism, microcredit, and rational economic woman. Economy and Society, 30(1), 18-37.

Raymond, L., L. Weldon, D. Kelly, X. Arriaga, A. Clark, (2014) Making Change: Norm-Based Strategies for Institutional Change to Address Intractable Problems Political Research Quarterly 67 (1), 197-211.

Raymond, L., \& Weldon, L. (2013). Informal Institutions and Strategies for Social Change Informal Institutions and Intractable Global Problems. West Lafayette Indiana: Purdue University.

Really? Campaign (2014). The Really? Campaign.. Retrieved from http://really.ubc.ca/

Ribot, J. (2002). Democratic decentralization of natural resources: institutionalizing popular participation. World Resources Institute. Retrieved from http://www.wri.org/publication/democratic-decentralization-natural-resourcesinstitutionalizing-popular-participat.

Robbins, P. (2006). Lawn People: How Grasses, Weeds, and Chemicals Make Us Who Ae Are. Philadelphia, PA: Temple University Press.

Rutherford, S. (2007). Green governmentality: insights and opportunities in the study of nature's rule. Progress in Human Geography, 31(3), 291-307

Rutten, R. (2006). Shame and Worker Activism: Emotional Dynamics in Face-to-Face Encounters. Qualitative Sociology, 29(3), 353-372.

Sultana, F. (2009a). Fluid lives: subjectivities, gender and water in rural Bangladesh. Gender, Place and Culture, 16(4), 427-444.

Sultana, F. (2009b). Community and participation in water resources management: gendering and naturing development debates from Bangladesh. Transactions of the Institute fo British Geographers, 34, 346-363.

Sultana, F. (2011). Suffering for water, suffering from water: Emotional geographies of resource access, control and conflict. Geoforum, 42, 163-172. 
United Nations Economic Commission for Europe (UNECE). (1998). Convention on Access to Information, Public Participation in Decision-Making and Access to Justice in Environmental Matters. Aahrus, Denmark: United Nations ECE. Available at: http://www.unece.org/fileadmin/DAM/env/pp/documents/cep43e.pdf.

Van Wijnendaele, B. (2011). Social Justice and the Politics of Emotions. Human Geography, 4(2), 1-15.

Van Wijnendaele, B. (2013). The Politics of Emotion in Participatory Processes of Empowerment and Change. Antipode, 46(1) 266-282.

Walby, S. (2005). Gender mainstreaming: Productive tensions in theory and practice. Social Politics: International Studies in Gender, State \& Society, 12(3), 321-343.

Westermann, O., Ashby, J., \& Pretty, J. (2005). Gender and social capital: The importance of gender differences for the maturity and effectiveness of natural resource management groups. World Development, 33(11), 1783-1799.

Woodward, K. \& J. Lea 2010. Geographies of Affect In S. Smith, R. Pain, S.A. Marston and J.P. Jones III (Eds). The Handbook of Social Geography (154-175). London: Sage.

Wong, S., \& Sharp, L. (2009). Making power explicit in sustainable water innovation: re-linking subjectivity, institution and structure through environmental citizenship. Environmental Politics, $18(1), 37-57$.

World Meteorological Organization (WMO). (1992). Dublin Statement on Water and Sustainable Development. Dublin: International Conference on Water and the Environment. Available at: http://www.gdrc.org/uem/water/dublin-statement.html.

Wutich, A. \& K. Ragsdale (2008). Water insecurity and emotional distress: Coping with supply, access, and seasonal variability of water in a Bolivian squatter settlement. Social Science \& Medicine, 67, 2116-2125.

Wutich, A. (2009). Intrahousehold Disparities in Women and Men's Experiences of Water Insecurity and Emotional Distress in Urban Bolivia. Medical Anthropology Quarterly, 23(4), 436454. 